\title{
XPS Investigation of Surface Reactivity of Electrode Materials: Effect of the Transition Metal
}

\author{
N. Andreu, ${ }^{\dagger}$ D. Flahaut, ${ }^{* \dagger}$ R. Dedryvère, ${ }^{\dagger}$ M. Minvielle, ${ }^{\dagger}$ H. Martinez, ${ }^{\dagger}$ and D. Gonbeau ${ }^{\dagger}$ \\ ${ }^{\dagger}$ IPREM, Université de Pau, Hélioparc Pau Pyrénées, 2 av. Pierre Angot, 64053 cedex 9 Pau, France \\ ${ }^{\ddagger}$ INL, Site Ecole Centrale de Lyon, Batiment F7, 36, Avenue Guy de Collongue, 69134 Ecully, France
}

\begin{abstract}
The role of the transition metal nature and $\mathrm{Al}_{2} \mathrm{O}_{3}$ coating on the surface reactivity of $\mathrm{LiCoO}_{2}$ and $\mathrm{LiNi}_{1 / 3} \mathrm{Mn}_{1 / 3} \mathrm{Co}_{1 / 3} \mathrm{O}_{2}$ (NMC) materials were studied by coupling chemisorption of gaseous probes molecules and X-ray photoelectron (XPS) spectroscopy. The XPS analyses have put in evidence the low reactivity of the $\mathrm{LiMO}_{2}$ materials toward basic gaseous probe $\left(\mathrm{NH}_{3}\right)$. The reactivity toward $\mathrm{SO}_{2}$ gaseous probe is much larger (roughly more than 10 times) and strongly influenced by the nature of metal. Only one adsorption mode (redox process producing adsorbed sulfate species) was observed at the $\mathrm{LiCoO}_{2}$ surface, while NMC materials exhibit sulfate and sulfite species at the surface. On the basis of XPS analysis of bare materials and previous theoretical work, we propose that the acid-base adsorption mode involving the $\mathrm{Ni}^{2+}$ cation is responsible for the sulfite species on the NMC surface. After $\mathrm{Al}_{2} \mathrm{O}_{3}$ coating, the surface reactivity was clearly decreasing for both $\mathrm{LiCoO}_{2}$ and $\mathrm{NMC}$ materials. In addition, for $\mathrm{LiCoO}_{2}$, the coating modifies the surface reactivity with the identification of both sulfate and sulfite species. This result is in line with a change in the adsorption mode from redox toward acid-base after $\mathrm{Al} /$ Co substitution. In the case of NMC materials, the coating induced a decrease of the sulfite species content at the surface. This phenomenon can be related to the cation mixing effect in the NMC.
\end{abstract}

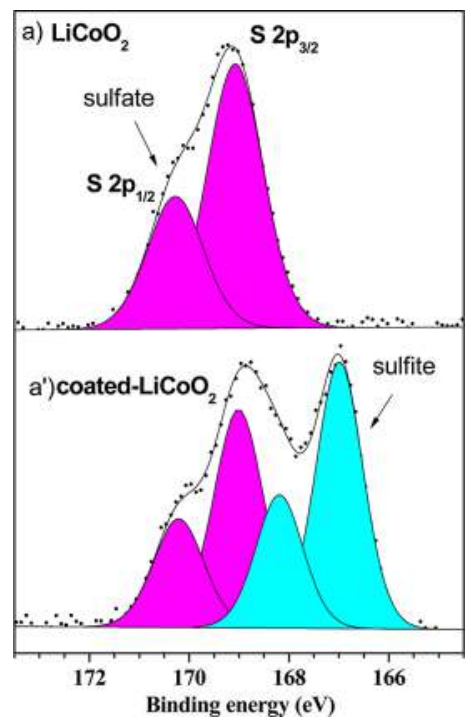

KEYWORDS: surface reactivity, XPS, $\mathrm{LiMO}_{2}$ electrode materials, $\mathrm{SO}_{2}$ and $\mathrm{NH}_{3}$ gas probes, adsorption mechanisms

\section{INTRODUCTION}

In the field of lithium ion battery, extensive studies have been carried out to improve the electrochemical performance of positive electrode materials. Among the layered $\mathrm{LiMO}_{2}(\mathrm{M}=$ 3d transition metal) with an $\alpha-\mathrm{NaFeO}_{2}$ structural type, $\mathrm{LiCoO}_{2}$ started the field and dominated the Li-ion battery positive electrode material market due to its high energy density and cycling stability. However, $\mathrm{LiCoO}_{2}$ suffers from the high cost of cobalt, safety issues, and a rather low capacity (only $50 \%$ of the $\mathrm{Li}$ can be exploited). In the last years, much research has been performed to explore alternative materials, including different cationic substitutions. Mixed transition metal oxides Li$\mathrm{Ni}_{x} \mathrm{Mn}_{x} \mathrm{Co}_{1-2 x} \mathrm{O}_{2} \quad(0.33 \leq x \leq 0.5)$ have received much attention ${ }^{1-6}$ because of attractive characteristics and a wide use depending on their composition. However, when these materials are charged to high voltages (beyond $4.2 \mathrm{~V}$ for $\mathrm{LiCoO}_{2}$ and $4.5 \mathrm{~V}$ for $\mathrm{LiNi}_{0.33} \mathrm{Mn}_{0.33} \mathrm{Co}_{0.33} \mathrm{O}_{2}$ (NMC)), appreciable capacity fading is observed upon cycling. This voltage increase, which leads to dissolution of transition metals in the electrolyte, is detrimental for the stability of the passivating film formed at the surface of the negative electrode.

The application of a metal oxide coating $\left(\mathrm{Al}_{2} \mathrm{O}_{3}, \mathrm{ZrO}_{2}\right.$, etc. $)^{7-11}$ at the surface has been revealed as an efficient method to improve the electrochemical performances at high voltages by modifying the reactivity of the active material surface toward the electrolyte. However, the exact mechanisms for the surface coating are not totally understood. Different reactions of $\mathrm{LiMO}_{2}$ materials with electrolyte containing alkyl carbonate solvents and $\mathrm{Li}$ salts are possible. They include the complex formation of thin surface films, acid-base reactions (with trace of $\mathrm{HF}$ always present in $\mathrm{LiPF}_{6}$-based electrolytes), and redox reactions (modifying the oxidation state of transition metal) resulting in the dissolution of transition metal ions into the electrolyte. $^{12}$

Surprisingly, in contrast with the numerous studies devoted to the bulk analyses of the positive electrode materials, the surface properties of these materials have received less attention. Relevant research works on the surface chemistry of positive electrode materials have been reported over the past decades using surface-sensitive techniques (Fourier transform infrared spectroscopy, X-ray photoelectron spectroscopy (XPS), electron microscopy, etc.), but further studies are necessary to address the surface reactivity of these materials. The surface properties of $\mathrm{LiCo}_{1-x} \mathrm{Al}_{x} \mathrm{O}_{2}$ materials were 
investigated as a function of the $\mathrm{Co} / \mathrm{Al}$ substitution. ${ }^{13}$ The results obtained by coupling adsorption of gaseous probe molecules and XPS analyses evidence that the $\mathrm{Al}$ substitution modifies the surface reactivity of $\mathrm{LiCoO}_{2}$, and density functional theory (DFT) was successfully applied for in-depth understanding of adsorption mechanisms. ${ }^{14}$

In the current contribution, this experimental approach was used for the first time to investigate the surface reactivity of bare and $\mathrm{Al}_{2} \mathrm{O}_{3}$-coated $\mathrm{NMC}$ and $\mathrm{LiCoO}_{2}$. The chemisorption of gaseous probe molecules $\left(\mathrm{NH}_{3}\right.$ and $\left.\mathrm{SO}_{2}\right)$ under controlled conditions is monitored by XPS, which allows an identification of the surface active sites and a quantitative determination of their concentration. It is part of a wider issue to better understand the surface reactivity of the positive electrode materials with respect to the electrolyte of Li-ion batteries in relation to the dissolution of transition metal ions into the electrolyte.

\section{MATERIAL AND METHODS}

2.1. Materials. The powder samples $\mathrm{LiCoO}_{2}$, coated $\mathrm{LiCoO}_{2}$, NMC, and coated NMC (purity of 99.85\%) were provided by Umicore Korea Ltd. and characterized in lab.

The powder X-ray diffraction (XRD patterns obtained on a SIEMENS D5000 X-ray diffractometer using $\mathrm{Cu} \mathrm{K} \alpha$ radiation $(\lambda=$ $1.5406 \AA$ )) were used to investigate crystallite structures of samples. The acceleration voltage and the applied current were $40 \mathrm{kV}$ and 25 $\mathrm{mA}$, respectively.

Crystallites size and shape were observed by a scanning electron microscopy (SEM) with Jeol Microprobe JAMP 9500F operating at the probe current of $1 \times 10^{-10} \mathrm{~A}$ and $30 \mathrm{keV}$ and a working distance (source/sample) of $\sim 20 \mathrm{~mm}$.

2.2. Gas Probe Adsorption. The adsorption experiments were performed on a Micromeritics 2920 Autochem analyzer. A reactor was specially designed to keep the sample (after gas adsorption) in helium atmosphere until its introduction into the XPS glovebox. The reactor was cleaned before each analysis by heating it at $773 \mathrm{~K}$ under argon flux during $1 \mathrm{~h}$. Powder samples $(0.1 \mathrm{~g})$ were introduced into the reactor and placed on a stainless frit. The samples were pretreated in argon flow at $623 \mathrm{~K}$ for $4 \mathrm{~h}$ to remove the water and physisorbed species from the surface. After that, the temperature was cooled and maintained at $353 \mathrm{~K}$ for 60 min under a helium flow. Thus, the chemisorption is performed from the same starting point, which avoids the impact of contamination conditions and storage.

The $\mathrm{SO}_{2}\left(\right.$ or $\left.\mathrm{NH}_{3}\right)$ adsorptions consisted in exposing the samples to a blend of $0.1 \% \mathrm{SO}_{2}$ in Helium (or $5 \% \mathrm{NH}_{3}$ in Helium) at $50 \mathrm{~mL}$. $\min ^{-1}$ for $15 \mathrm{~min}$ at $353 \mathrm{~K}$. Finally, the samples were flushed in $\mathrm{He}$ flow at $353 \mathrm{~K}$ for $60 \mathrm{~min}$ to remove the physisorbed species from the oxide surface. XPS analyses were performed on samples without any contact with atmosphere. We were able to evaluate the gas probe amount that flowed through the samples on the basis of the Knudsen equation. The gas flow, which represents the amount of gas probe molecules in contact with the sample surface per time and surface unit, is given by the following equation

$$
F=\frac{N P}{\sqrt{2 M R T \pi}}
$$

with $N$ the Avogadro number, $P$ the pressure, $M$ the molecular weight of the reactive gas, $R$ the ideal gas constant, and $T$ the temperature. With our operating conditions $\left(P\left(\mathrm{SO}_{2}\right)=1.013 \times 10^{2} \mathrm{~Pa}\right)$, this corresponds to the adsorption of a monolayer of gas probe molecules.

2.3. X-ray Photoelectron Spectroscopy. The XPS analyses were performed with a Kratos Axis Ultra spectrometer using a focused monochromatized $\mathrm{Al} \mathrm{K} \alpha$ radiation $(h \nu=1486.6 \mathrm{eV})$. The pressure in the analysis chamber was ca. $5 \times 10^{-9} \mathrm{mbar}$. The samples, which were submitted to chemisorption, are installed on the sample holder directly in the glovebox ( $1 \mathrm{ppm}$ in $\mathrm{O}_{2}$ and $\mathrm{H}_{2} \mathrm{O}$ ) connected to the spectrometer, to avoid oxidation and contamination of the surface by reaction with the ambient atmosphere. The binding energy (B.E.) scale was calibrated from the carbon contamination (always present at surface of materials) using the $\mathrm{C} 1 \mathrm{~s}$ peak at $285 \mathrm{eV}$. Core peaks were analyzed using a nonlinear Shirley-type background, and peak positions and areas were obtained by a weighted least-squares fitting of model curves (70\% Gaussian, 30\% Lorentzian) to the experimental data. Quantification was performed on the basis of Scofield's relative sensitivity factors. ${ }^{15}$ All the adsorption/XPS coupling experiments were performed three times to check the reproducibility of the results. Only the strongest acidic and basic sites can be evidenced, because the weakest sites cannot retain the gaseous probes under the ultrahigh vacuum conditions $\left(\sim 1 \times 10^{-9} \mathrm{mbar}\right)$ of XPS analyses. Moreover, we tested the effect of the duration time under ultrahigh vacuum on the surface composition after $\mathrm{SO}_{2}$ adsorption. We did not observe any change in the S/M ratio whatever the time inside the XPS was.

\section{RESULTS AND DISCUSSION}

3.1. Structural Characterization. The XRD patterns (Supporting Information, Figures S-1 and S-2) confirm the $\alpha$ $\mathrm{NaFeO}_{2}$-type structure $(R \overline{3} m$ space group) of the bare and coated $\mathrm{LiCoO}_{2}$ and NMC samples. The $\mathrm{LiCoO}_{2}$, coated $\mathrm{LiCoO}_{2}, \mathrm{NMC}$, and coated NMC samples include spherelike particles and present an agglomerated status with a homogeneous size distribution of 5-20 $\mu \mathrm{m}$ (Supporting Information, Figures S-3 and S-4). The size and shape of particles are roughly the same for all materials as the specific areas, determined by the Brunauer-Emmer-Teller method close to $0.30 \pm 0.03 \mathrm{~m}^{2} \cdot \mathrm{g}^{-1}$ (Supporting Information, Table S$1)$.

3.2. X-ray Photoelectron Spectroscopy Study. 3.2.1. Bare $\mathrm{LiCoO}_{2}$ and $\mathrm{LiNi}_{0.33} \mathrm{Mn}_{0.33} \mathrm{Co}_{0.33} \mathrm{O}_{2}$ Materials. All core peaks of bare $\mathrm{LiCoO}_{2}$ and $\mathrm{NMC}$ materials were recorded. The corresponding binding energies and atomic percentages are reported in Tables 1 and 2.

Table 1. Binding Energy (eV) and Atomic Percentages (\%) of $\mathrm{Li}, \mathrm{Co}, \mathrm{Al}, \mathrm{C}$, and $\mathrm{O}$ Elements Obtained from XPS Spectra of Bare and Coated $\mathrm{LiCoO}_{2}$

\begin{tabular}{|c|c|c|c|c|}
\hline & & & coat & $\mathrm{iCoO}_{2}$ \\
\hline & B.E. $(\mathrm{eV})$ & $\%$ & B.E. $(\mathrm{eV})$ & $\%$ \\
\hline Li 1s & 54.3 & 14.6 & 54.3 & 14.8 \\
\hline & 55.5 & 3.3 & 55.4 & 2.1 \\
\hline & & $17.9 \pm 0.9$ & & $16.9 \pm 0.9$ \\
\hline Co $2 p_{3 / 2}$ & 779.7 & $12.5 \pm 0.2$ & 779.7 & $8.3 \pm 0.2$ \\
\hline $\mathrm{Al} 2 \mathrm{p}$ & & & 73.8 & $4.6 \pm 0.2$ \\
\hline $\mathrm{C} 1 \mathrm{~s}$ & 285.0 & 22.2 & 285.0 & 22.1 \\
\hline & 286.2 & 1.7 & 286.2 & 2.4 \\
\hline & 288.7 & 1.5 & 288.8 & 1.4 \\
\hline & 290.0 & 2.0 & 289.9 & 1.2 \\
\hline & & $27.4 \pm 0.3$ & & $27.1 \pm 0.3$ \\
\hline O $1 \mathrm{~s}$ & 529.5 & 23.3 & 529.5 & 23.1 \\
\hline & 531.6 & 18.9 & 531.6 & 20.1 \\
\hline & & $42.2 \pm 0.2$ & & $43.2 \pm 0.2$ \\
\hline
\end{tabular}

The Co $2 p$ core peaks of both materials are shown in Figure 1. Because of spin-orbit coupling, each spectrum is split in two parts (Co $2 \mathrm{p}_{3 / 2}$ and Co $2 \mathrm{p}_{1 / 2}$ ), with an intensity ratio close to $2 / 1$. The main Co $2 \mathrm{p}_{3 / 2}$ components are located at 779.7 and $779.9 \mathrm{eV}$, respectively, for $\mathrm{LiCoO}_{2}$ and NMC. Each peak presents a satellite at $+10 \mathrm{eV}$ with a relative area compared to that of Co $2 p_{3 / 2}$ component of $\sim 9-10 \%$. The same is observed for the Co $2 \mathrm{p}_{1 / 2}$ component. These "shakeup" satellites result from the metal-ligand charge transfer during the photo- 
Table 2. Binding Energy (eV) and Atomic Percentages (\%) of $\mathrm{Li}, \mathrm{Co}, \mathrm{Al}, \mathrm{C}$, and $\mathrm{O}$ Elements Obtained from XPS Spectra of Bare and Coated NMC

\begin{tabular}{|c|c|c|c|c|}
\hline & \multicolumn{2}{|c|}{$\mathrm{Li}\left(\mathrm{Ni}_{1 / 3} \mathrm{Co}_{1 / 3} \mathrm{Mn}_{1 / 3}\right) \mathrm{O}_{2}$} & \multicolumn{2}{|c|}{$\begin{array}{l}\text { coated } \mathrm{Li}\left(\mathrm{Ni}_{1 / 3} \mathrm{Co}_{1 / 3} \mathrm{Mn}_{1 / 3}\right) \\
\mathrm{O}_{2}\end{array}$} \\
\hline & B.E. $(\mathrm{eV})$ & $\%$ & B.E. $(\mathrm{eV})$ & $\%$ \\
\hline \multirow[t]{3}{*}{ Li 1s } & 54.3 & 14.4 & 54.3 & 12.8 \\
\hline & 55.6 & 1.4 & 55.7 & 2.0 \\
\hline & & $15.8 \pm 0.9$ & & $14.8 \pm 0.9$ \\
\hline $\mathrm{Ni} 2 \mathrm{p}_{3 / 2}$ & 854.5 & $3.3 \pm 0.1$ & 854.5 & $4.6 \pm 0.1$ \\
\hline Co $2 \mathrm{p}_{3 / 2}$ & 779.9 & $2.8 \pm 0.1$ & 779.9 & $3.3 \pm 0.1$ \\
\hline $\operatorname{Mn} 2 \mathrm{p}_{3 / 2}$ & 642.3 & $4.6 \pm 0.1$ & 642.3 & $6.0 \pm 0.1$ \\
\hline Al $2 p$ & & & 73.8 & $3.9 \pm 0.2$ \\
\hline \multirow[t]{5}{*}{ C 1 s } & 285.0 & 25.2 & 285.0 & 11.8 \\
\hline & 286.3 & 3.3 & 286.1 & 1.9 \\
\hline & 289.0 & 1.6 & 288.4 & 1.1 \\
\hline & 290.1 & 1.3 & 289.9 & 1.2 \\
\hline & & $31.4 \pm 0.3$ & & $15.9 \pm 0.3$ \\
\hline \multirow[t]{3}{*}{$\mathrm{O} 1 \mathrm{~s}$} & 529.4 & 20.0 & 529.4 & 25.5 \\
\hline & 531.9 & 22.1 & 531.4 & 26.1 \\
\hline & & $42.1 \pm 0.2$ & & $51.5 \pm 0.2$ \\
\hline
\end{tabular}

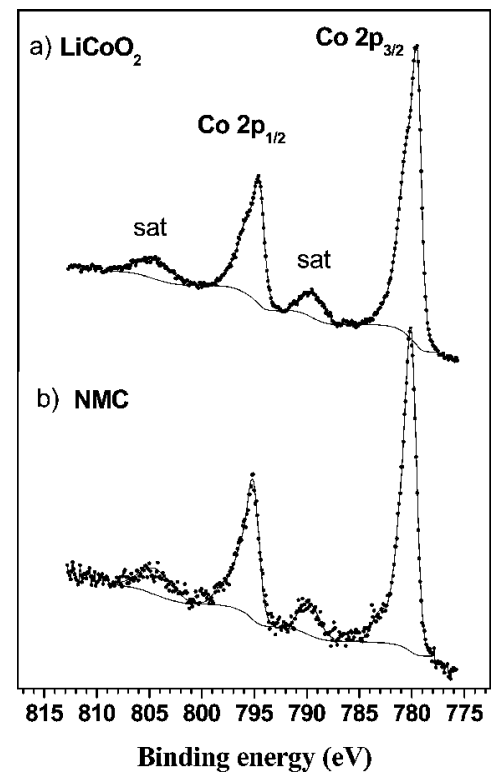

Figure 1. Co $2 p$ core peaks of bare $\mathrm{LiCoO}_{2}$ (a) and NMC (b).

emission process as detailed in a previous paper. ${ }^{13}$ The position and intensity of these satellite peaks are characteristic of $\mathrm{Co}^{3+}$ ions in $\mathrm{NMC}$ as $\mathrm{LiCoO}_{2}$.

The Ni $2 p$ core peak of NMC (Figure 2) reveals two main components at $854.5 \mathrm{eV}\left(\mathrm{Ni} 2 \mathrm{p}_{3 / 2}\right)$ and $872.1 \mathrm{eV}\left(\mathrm{Ni} 2 \mathrm{p}_{1 / 2}\right)$ associated with satellite peaks located at 861.1 and $878 \mathrm{eV}$, respectively. Concerning the oxidation state of nickel, note that the $\mathrm{Ni} 2 \mathrm{p}$ peak shape of $\mathrm{NiO}$ and $\mathrm{LiNiO}_{2}$ are comparable, but some differences are observed, for example, the well-known splitting of the $\mathrm{Ni} 2 \mathrm{p}$ main line for $\mathrm{NiO}$ (not present in $\mathrm{LiNiO}_{2}$ ) and a higher intensity of the satellite in the case of NiO. ${ }^{16,17}$ A similar $I_{\text {sat }} / I_{\text {main peak }}$ ratio value here obtained (40\%), close to that reported by Dupin et al., ${ }^{17}$ allows us to conclude that $\mathrm{Ni}^{2+}$ is present at the surface of the NMC sample without excluding a weak amount of $\mathrm{Ni}^{3+}$ at the surface.

As for cobalt and nickel, the Mn $2 \mathrm{p}$ spectrum is split in two components at $642.3 \mathrm{eV}\left(\mathrm{Mn} \mathrm{2} \mathrm{p}_{3 / 2}\right)$ and $653.8 \mathrm{eV}\left(\mathrm{Mn} \mathrm{2} \mathrm{p}_{1 / 2}\right)$,

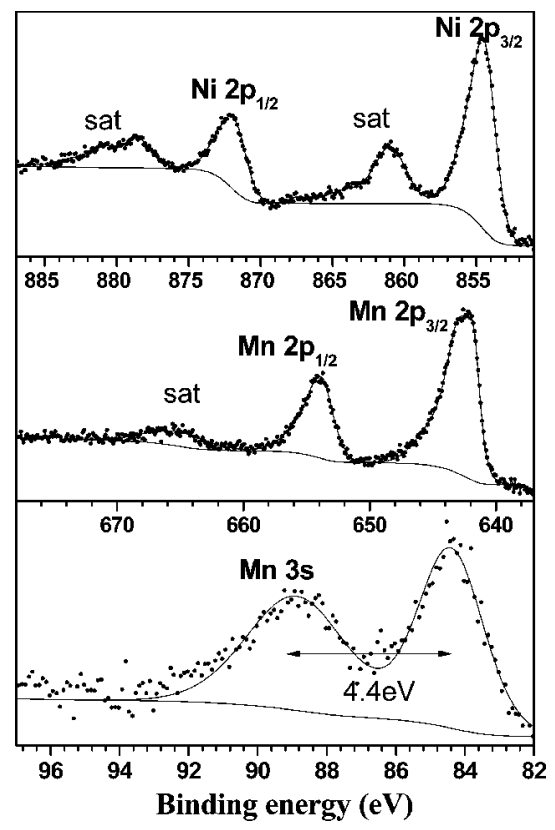

Figure 2. Ni 2p, Mn 2p, and Mn 3s core peaks of bare NMC.

with a satellite peak located at $665.8 \mathrm{eV}$ (Figure 2). These binding energies ${ }^{18}$ are consistent with a $\mathrm{Mn}^{4+}$ cation as reported for manganese oxide. The $\mathrm{Mn} 3 \mathrm{~s}$ core peak allows us to confirm the oxidation state of $\mathrm{Mn}$. Indeed, the splitting of this peak (resulting from the exchange interaction of $\mathrm{Mn} 3 \mathrm{~s}$ and $3 \mathrm{~d}$ electrons, leading to two photoemission final states) is dependent on the number of $3 \mathrm{~d}$ electrons, and the expected values are $\sim 6.5 \mathrm{eV}$ for $\mathrm{Mn}^{2+}, 5.5 \mathrm{eV}$ for $\mathrm{Mn}^{3+}$, and $4.5 \mathrm{eV}$ for $\mathrm{Mn}^{4+} \cdot{ }^{19,20}$ The splitting value here obtained at $\sim 4.4 \mathrm{eV}$ is characteristic of $\mathrm{Mn}^{4+}$. As a summary, XPS analyses for NMC reveal the presence of $\mathrm{Mn}^{4+}, \mathrm{Co}^{3+}$, and $\mathrm{Ni}^{2+}$ in agreement with previous attributions (X-ray absorption spectroscopy, theoretical calculations, ${ }^{21}$ and $\mathrm{XPS}^{22}$ ).

For $\mathrm{LiCoO}_{2}$ and NMC materials, the $\mathrm{O}$ 1s spectrum consists of two peaks at $529.5 \mathrm{eV}$, characteristic of $\mathrm{O}^{2-}$ anions of the crystalline network, and at $\sim 531.6 \mathrm{eV}$ (Tables 1 and 2) that can be assigned to surface $\mathrm{Li}_{2} \mathrm{CO}_{3}$ and to weakly adsorbed species. This last peak can be also attributed to oxygen anions of the extreme surface with a deficient coordination. ${ }^{23}$

The 50-80 eV B.E. range is of particular interest because it includes the Ni 3p, Co 3p, Li 1s, and Mn 3p spectra (Figure $3 \mathrm{a}, \mathrm{b})$. For $\mathrm{LiCoO}_{2}$, the Co $3 \mathrm{p}$ spectrum consists of a main line and a shakeup satellite at 61 and $71 \mathrm{eV},{ }^{13}$ respectively (the latter of which is hidden by $\mathrm{Ni} 3 \mathrm{p}$ in NMC). For the NMC material, this region also includes the $\mathrm{Mn} 3 p$ at $49.7 \mathrm{eV}^{24}$ and the $\mathrm{Ni} 3 \mathrm{p}$ at $67.3 \mathrm{eV}$ with a satellite peak at $73.1 \mathrm{eV}$, characteristic of $\mathrm{Ni}^{2+} \cdot{ }^{24}$

These results confirm the previous attribution $\left(\mathrm{Mn}^{4+}, \mathrm{Co}^{3+}\right.$, and $\mathrm{Ni}^{2+}$ ). For both compounds the $\mathrm{Li} 1 \mathrm{~s}$ spectrum consists of two peaks at $54.3 \mathrm{eV}$ assigned to $\mathrm{Li}^{+}$ions of the lamellar oxide and at $55.5 \mathrm{eV}$ attributed to lithium carbonate $\mathrm{Li}_{2} \mathrm{CO}_{3}$, which is present at the surface of the material. The stoichiometry of the samples was checked by XPS, and the results are close to the nominal composition (Tables 1 and 2).

3.2.2. Coated Materials $\mathrm{LiCoO}_{2}$ and $\mathrm{LiNi}_{0.33} \mathrm{Mn}_{0.33} \mathrm{Co}_{0.33} \mathrm{O}_{2}$. The impact of the alumina coating on $\mathrm{LiCoO}_{2}$ and $\mathrm{NMC}$ materials was analyzed by XPS. The Al 3p, Ni 3p, Co 3p, Li 1s, and $\mathrm{Mn} 3 \mathrm{p}$ spectra are represented for the coated $\mathrm{LiCoO}_{2}$ and NMC in Figure $3 a^{\prime}, b^{\prime}$. No change is observed for the Ni 3p, Co 

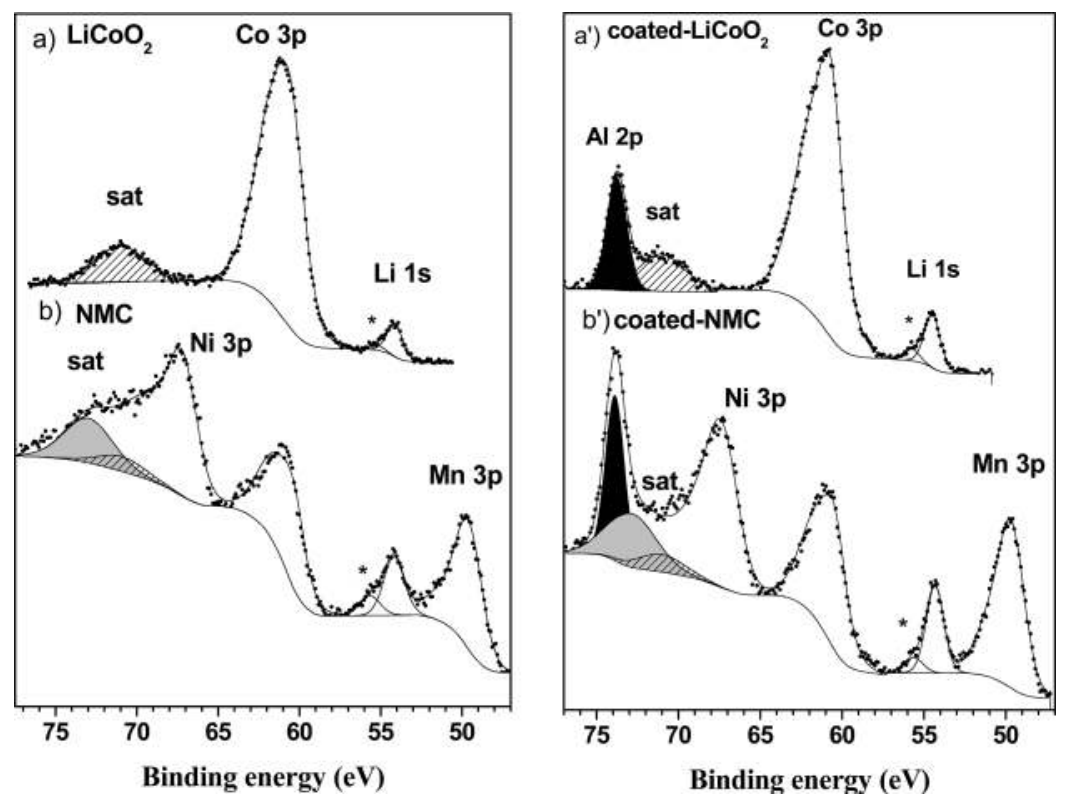

Figure 3. $\mathrm{Al} 2 \mathrm{p}$, Ni 3p, Co 3p, Mn 3p, and $\mathrm{Li} 1$ s core peaks of bare and coated $\mathrm{LiCoO}_{2}\left(\mathrm{a}, \mathrm{a}^{\prime}\right)$ and $\mathrm{NMC}\left(\mathrm{b}, \mathrm{b}^{\prime}\right)$. The hatched and gray area correspond, respectively, to the satellite of the $\mathrm{Co} 3 \mathrm{p}$ and $\mathrm{Ni} 3 \mathrm{p}$ core peaks. The black area is assigned to the $\mathrm{Al} 2 \mathrm{p}$ core peak.

3p, Li 1s, and Mn 3p spectra compared to the bare materials (Figure 3a,b). This is a proof that the oxidation states of the metals were not modified by the alumina coating. The alumina coating of $\mathrm{LiCoO}_{2}$ and NMC samples is well-characterized by the presence of the $\mathrm{Al} 2 \mathrm{p}$ core peak at $73.8 \mathrm{eV}$ characteristic of $\mathrm{Al}$ atoms in an oxygen environment. The relative proportion of aluminum is roughly the same for both materials (Tables 1 and 2). The chemical nature of the coating seems to be identical.

3.3. Surface Reactivity. Transition metal oxide surfaces consist of coordinatively unsaturated metallic cations and oxygen anions with, possibly, adsorbed hydroxyl groups. According to their electronic and chemical properties, these surfaces behave differently in their interaction with adsorbed molecules. Two types of adsorption mechanisms, namely, dissociative or nondissociative, can be distinguished depending on the involved interactions. Different kinds of interactions can be categorized:

- weak and nondirectional electrostatic interactions that characterize the nondissociative mechanism identified as reversible physisorption,

- acid-base type interactions. In that case, the adsorbate can play the role of lone pair acceptor or donor,

- redox type interactions. In that case, the oxidation state of the adsorbate changes according to a direct transfer of electrons to or from the surface.

According to the weak interactions involved in physisorption such phenomenon is not considered in the ultravacuum conditions of XPS analyses.

In this work, our objective was to obtain information on the nature and the amount of the strongest active surface sites of electrode materials by coupling chemisorption of gas-phase probes and XPS analyses, an experimental approach widely used in the catalysis field. ${ }^{25} \mathrm{NH}_{3}$ and $\mathrm{SO}_{2}$ were chosen because nitrogen and sulfur are not present in the pristine electrodes, and these elements also exhibit a large B.E. scale. $\mathrm{NH}_{3}$ can be retained on the surface of oxides through different interactions:

- interaction with a Brönsted acidic site (Scheme 1a)); it involves a transfer of proton from surface hydroxyl to the adsorbate forming $\mathrm{NH}_{4}{ }^{+}$and resulting in a $\mathrm{N}$ 1s peak at $\sim 401.5-402.8 \mathrm{eV}^{26}$

Scheme 1. Schematic Representation of the Adsorption Mechanisms of $\mathrm{NH}_{3}$ on (a) Brönsted and (b) Lewis acid sites

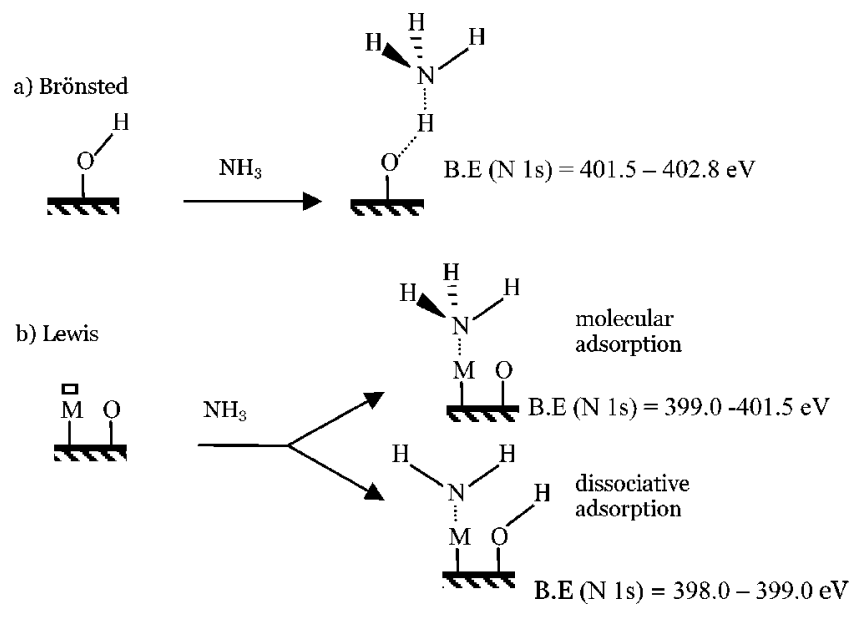

- coordination to an electron deficient metal atom ; it takes place by donation of the lone pair on nitrogen to a Lewis acid site on the surface with formation of a dative bond (Scheme 1b)); this results in a N 1s peak at $\sim 399.0-$ $401.5 \mathrm{eV}^{25}$ depending on the charge transfer and the acidic strength of the site.

- interaction dissociative with a Lewis acid site (Scheme 1b) characterized by a N 1s peak at $\sim 398.0-399.0 ~ e V .{ }^{27}$

$\mathrm{SO}_{2}$ can act as a donor or acceptor, but it can be also oxidized or reduced with electron transfer. Several interactions of $\mathrm{SO}_{2}$ with a metal oxide surface can be distinguished:

- interaction between sulfur and oxygen from the surface leading to the formation of sulfite species $\left(\mathrm{SO}_{3}^{2-}\right.$, Scheme $2 \mathrm{a})$, characterized by a B.E. of the $S 2 \mathrm{p}_{3 / 2}$ core peak at 
$\sim 167.5 \mathrm{eV}^{28}$ (without any modification of the oxidation state of the sulfur);

Scheme 2. Schematic Representation of the Adsorption Mechanisms of $\mathrm{SO}_{2}$ on Oxygen (a) and Lewis (b) Sites

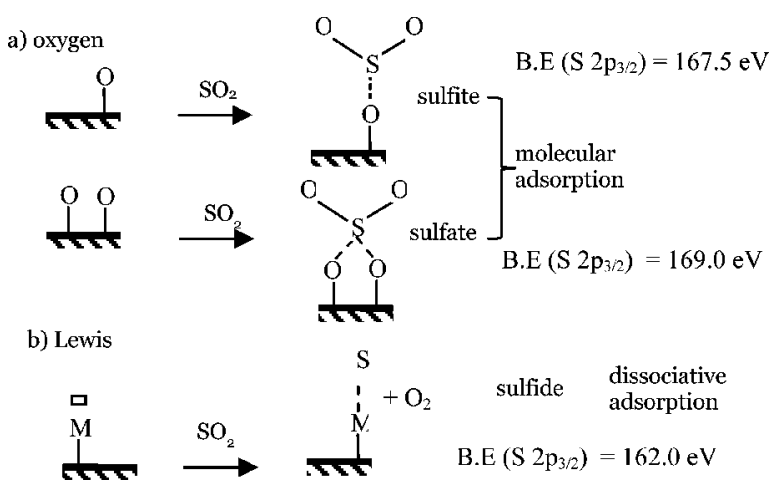

- interaction between sulfur and two oxygen from the surface with the formation of sulfate species $\left(\mathrm{SO}_{4}^{2-}\right.$, Scheme $2 \mathrm{a}$ ) associated with a B.E. of the $S 2 \mathrm{p}_{3 / 2}$ peak at $\sim 169.0 \mathrm{eV}^{29}$

- interaction of the sulfur atom with a metal from the surface by dissociative mechanism (Scheme $2 \mathrm{~b}$ ) resulting in a sulfide species $\left(\mathrm{S}^{2-}\right.$, B.E. $\left.\left(\mathrm{S} 2 \mathrm{p}_{3 / 2}\right) \approx 162.0 \mathrm{eV}\right){ }^{30}$

In this way, the identification of adsorbed species is possible, and the involved mechanisms are elucidated. Quantitative information can also be obtained with the evaluation of the N/ $\mathrm{M}$ and S/M atomic ratios, deduced from XPS analysis of the core peaks of the adsorbed molecules $\left(\mathrm{N} 1 \mathrm{~s}\right.$ and $\mathrm{S} 2 \mathrm{p}$ for $\mathrm{NH}_{3}$ and $\mathrm{SO}_{2}$ gas probes, respectively) as well as the metals $(\mathrm{M} 2 \mathrm{p}=$ Co $2 p$ for $\mathrm{LiCoO}_{2}$ and $\mathrm{M} 2 \mathrm{p}=\mathrm{Ni} 2 \mathrm{p}+\mathrm{Mn} 2 \mathrm{p}+\mathrm{Co} 2 \mathrm{p}$ for $\mathrm{NMC}$ ) of the material. It is thus possible to monitor the impact of the transition metal nature and of the coating on the surface reactivity.

3.3.1. $\mathrm{NH}_{3}$ Adsorption. We performed XPS analyses of the four samples after $\mathrm{NH}_{3}$ adsorption. The $\mathrm{N}$ 1s spectra of bare and coated $\mathrm{LiCoO}_{2}$ and $\mathrm{NMC}$ are presented in Figure 4. In all cases, only one component of the $\mathrm{N}$ 1s peak was identified at $399.6 \mathrm{eV}$ assigned to Lewis acid sites correlated to the transition metal setting at the surface. We did not identify any influence of the transition metal $\mathrm{M}$ in $\mathrm{LiMO}_{2}$ and coating on the nature of the adsorbed species. Moreover, no detectable component at $\sim 402.5 \mathrm{eV}\left(\mathrm{NH}_{4}^{+}\right.$species) assigned to Brönsted acid sites is observed. This result evidences that hydroxyl groups are not present in significant amount at the surface of these materials. $^{31}$

The N/M ratio is $\sim 0.025 \pm 0.003$ and $0.020 \pm 0.003$ for bare and coated $\mathrm{LiCoO}_{2}$ and $0.050 \pm 0.005$ and $0.040 \pm 0.005$ for bare and coated NMC, respectively. The acid sites concentration is thus larger for NMC, and the acidity of the surface is decreasing to a lesser extent after $\mathrm{Al}_{2} \mathrm{O}_{3}$ coating for $\mathrm{LiCoO}_{2}$ and NMC.

The reactivity of $\mathrm{LiMO}_{2}$ oxides toward basic probe is extremely low. We can advance the hypothesis that the concentration of acid sites is very poor at the surface as reported previously for transition metal oxide materials. ${ }^{14}$ Whatever the acid sites concentration, the low reactivity could be explained if the acid sites are very weak resulting in a partial desorption under ultrahigh vacuum conditions of the XPS. We point out that the atomic ratios $\mathrm{N} / \mathrm{M}$ and $\mathrm{N} /(\mathrm{M}+\mathrm{Al})$ of bare

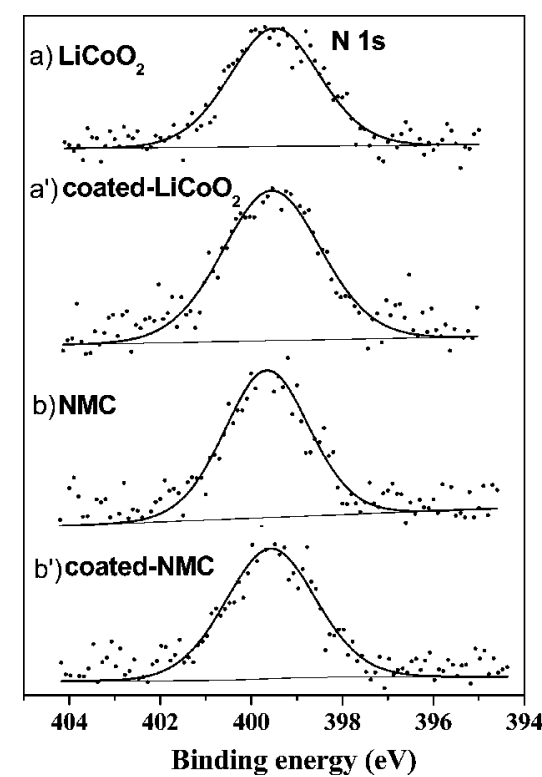

Figure 4. $\mathrm{N} 1$ s core peaks after $\mathrm{NH}_{3}$ adsorption of bare and coated $\mathrm{LiCoO}_{2}\left(\mathrm{a}, \mathrm{a}^{\prime}\right)$ and $\mathrm{NMC}\left(\mathrm{b}, \mathrm{b}^{\prime}\right)$.

and coated NMC are twofold higher compared to bare and coated $\mathrm{LiCoO}_{2}$. Within SEM investigation, we demonstrated that the materials have the same specific area and the same particle sizes. Therefore, this reactivity enhancement can be related only to the change in the nature of the transition metals $\mathrm{Ni}^{2+}$ and/or $\mathrm{Mn}^{4+}$ in NMC.

As a small decrease of the $\mathrm{N} / \mathrm{M}$ and $\mathrm{N} /(\mathrm{M}+\mathrm{Al})$ ratio is revealed for the coated materials, these results suggest that the coating acts as a protection layer by a decrease of the acid sites concentration after alumina coating, which is consistent with the very low reactivity of $\mathrm{Al}_{2} \mathrm{O}_{3}$ toward $\mathrm{NH}_{3}(\mathrm{~N} / \mathrm{Al}=0.006){ }^{14}$

3.3.2. $\mathrm{SO}_{2}$ Adsorption. 3.3.2.1. Bare and Coated $\mathrm{LiCoO}_{2}$. Figure 5 presents the $\mathrm{S} 2 \mathrm{p}$ spectra of bare and coated $\mathrm{LiCoO}_{2}$ after $\mathrm{SO}_{2}$ adsorption. Because of spin-orbit coupling, each $\mathrm{S} 2 \mathrm{p}$

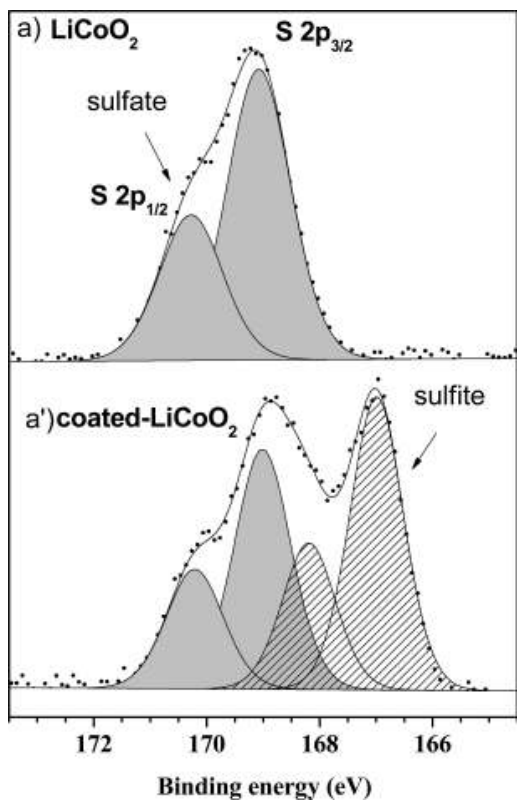

Figure 5. S $2 \mathrm{p}$ core peaks after $\mathrm{SO}_{2}$ adsorption of bare (a) and coated $\mathrm{LiCoO}_{2}\left(\mathrm{a}^{\prime}\right)$. 
signal consists of a $2 \mathrm{p}_{3 / 2}-2 \mathrm{p}_{1 / 2}$ doublet with a $1.2 \mathrm{eV}$ splitting. A unique $S 2 p$ doublet relative to sulfate species is observed for bare $\mathrm{LiCoO}_{2}$, whereas both sulfate (B.E. S $2 \mathrm{p}_{3 / 2}=169.0 \mathrm{eV}$ ) and sulfite (B.E. S $2 \mathrm{p}_{3 / 2}=167.0 \mathrm{eV}$ ) species are identified for the coated $\mathrm{LiCoO}_{2}$. The $\mathrm{S} / \mathrm{M}$ ratio is 0.27 for bare and 0.19 for coated $\mathrm{LiCoO}_{2}$. Thus, $\mathrm{Al}_{2} \mathrm{O}_{3}$ coating of $\mathrm{LiCoO}_{2}$ electrode leads to a decrease of the reactivity toward the $\mathrm{SO}_{2}$ probe.

Moreover, we highlight that the nature of the adsorbed species is strongly driven by the nature of the metal, a result totally consistent with our previous work. Indeed, we have explored ${ }^{13}$ the surface reactivity of $\mathrm{LiCo}_{1-x} \mathrm{Al}_{x} \mathrm{O}_{2}$ solid solutions as compared to $\mathrm{LiCoO}_{2}$ and evidenced that the $\mathrm{Al}$ substitution modifies the surface reactivity of $\mathrm{LiCoO}_{2}$. Indeed, only sulfate species are identified for $\mathrm{LiCoO}_{2}$, whereas both sulfate and sulfite species are characterized for the $\mathrm{LiCo}_{1-x} \mathrm{Al}_{x} \mathrm{O}_{2}$ solid solutions. Concomitant theoretical studies have provided a clearer view of the adsorption mechanism of the $\mathrm{SO}_{2}$ gas probe on the $\mathrm{LiCoO}_{2}$ surface using DFT calculations to explore the thermodynamically favorable $\mathrm{SO}_{2}$ adsorption modes on $\mathrm{LiCoO}_{2}$ and $\alpha-\mathrm{LiAlO}_{2}{ }^{14}$ This study demonstrates that the $\alpha$ $\mathrm{LiAlO}_{2}$ surface reactivity is governed by the Lewis basicity of surface oxide anions. The surface reactivity of the $\mathrm{LiCoO}_{2}$ appears much more complex with the identification of two adsorption modes: a redox process producing adsorbed sulfatelike $\left(\mathrm{SO}_{4}^{2-}\right)$ species and a less energetically favorable acid base process leading to sulfite-like $\left(\mathrm{SO}_{3}^{2-}\right)$ species. The results demonstrate that the modification of the surface reactivity induced by the substitution of the Co by $\mathrm{Al}$ ions is correlated to a change from an adsorption mode controlled by redox properties for $\mathrm{LiCoO}_{2}$ to a less energetically favorable adsorption mode controlled by acid-base properties for $\alpha$ $\mathrm{LiAlO}_{2}$. By reference to the redox standard potentials, we could argue that the $\mathrm{Co}^{3+}$ cation is much more reducible than the $\mathrm{Al}^{3+}$ cation in relation to the oxidation of the $\mathrm{SO}_{2}$ gas probe into sulfate species as evidenced by a significant charge transfer $\left(\sim 1.1 \mathrm{e}^{-}\right)$from $\mathrm{SO}_{2}$ to the surface.

3.3.2.2. $\mathrm{LiNi}_{1 / 3} \mathrm{Mn}_{1 / 3} \mathrm{CO}_{1 / 3} \mathrm{O}_{2}$ and Coated $\mathrm{Li}$ $\mathrm{Ni}_{1 / 3} \mathrm{Mn}_{1 / 3} \mathrm{Co}_{1 / 3} \mathrm{O}_{2}$. The surface reactivity toward $\mathrm{SO}_{2}$ gas probe was also studied on the bare and coated NMC to evaluate the impact of both the transition metal nature and the coating on the reactivity. We first ensure that the adsorption did not modify the materials, oxidation states of the elements, and stoichiometry. The Figures 5a and 6a exhibit the strong impact of the $\mathrm{Ni}$ and $\mathrm{Mn}$ substitution on the nature of the adsorbed species on NMC material. Indeed, sole sulfate species were detected for bare $\mathrm{LiCoO}_{2}$, whereas we identify two $\mathrm{S} 2 \mathrm{p}$ doublets associated with sulfate and sulfite species for NMC materials (Figure 6a). The $\mathrm{S} / \mathrm{M}$ ratio is $\sim 0.31$ for NMC and 0.27 for $\mathrm{LiCoO}_{2}$ samples.

According to these results, the nature of the $\mathrm{M}$ cation in the $\mathrm{LiMO}_{2}$ materials has a strong influence on the surface reactivity especially on the nature of the adsorbed species. We previously discussed the incidence of the adsorption mode on the nature of the adsorbed species on $\mathrm{LiCoO}_{2}$ and coated $\mathrm{LiCoO}_{2}$ surfaces. The same reasoning can be driven to elucidate the change of the adsorbed species for bare $\mathrm{LiCoO}_{2}$ and $\mathrm{NMC}$ surfaces considering that only the manganese and nickel could be involved in the modification of the surface reactivity. The theoretical study on $\mathrm{LiCoO}_{2}$ and $\alpha-\mathrm{LiAlO}_{2}$ has explained that, beside the fact that the sulfate species are only present in the case of a reducible cation, the redox adsorption mode is more favorable than the acid-base mode. From the characteristics of the transition metals present in the NMC electrodes, the

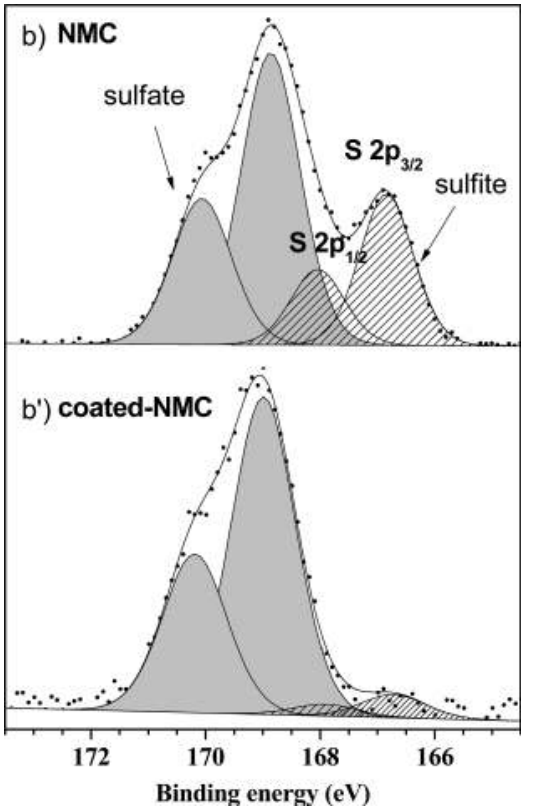

Figure 6. $\mathrm{S} 2 \mathrm{p}$ core peaks after $\mathrm{SO}_{2}$ adsorption of bare (b) and coated NMC $\left(b^{\prime}\right)$.

manganese can, as well as the cobalt, be reduced during the adsorption process. However, the $\mathrm{Ni}^{2+}$ cation is hard to reduce leading to an acid-base adsorption mode that could explain the presence of sulfite species on the bare NMC surface. This interpretation may be confirmed by further investigation.

For the coated NMC, a clear decrease of the S/M ratio is observed compared to the bare NMC (from 0.31 to 0.10 ), which shows that the surface of coated NMC is much less reactive than that of bare NMC. The same trend was noted for $\mathrm{LiCoO}_{2}$, but the influence of coating appears more important for NMC. In addition, for the coated NMC, sulfate and sulfite species are identified as for the bare NMC, but with a lower proportion of sulfite ( $7 \%$ compared to $32 \%$ for bare NMC, Figure $\left.6 b, b^{\prime}\right)$. This is in contrast to the coating impact on the $\mathrm{LiCoO}_{2}$ materials although the chemical nature (B.E. Al $2 \mathrm{p}=$ $73.8 \mathrm{eV}$ ) and the relative proportion of aluminum (3.9\% for $\mathrm{NMC}$ ) are roughly the same as for $\mathrm{LiCoO}_{2}$. One can propose that the alumina coating recovers one part of the surface that is constitutive not only of redox active sites for the $\mathrm{LiCoO}_{2}$ materials but also acid-base and redox active sites for the NMC materials. However, interactions between transition ion metals are very complex in NMC materials, resulting, for example, in a cation mixing effect, ${ }^{32}$ and preclude discussion of the coating impact without additional studies.

\section{CONCLUSION}

In this work, our aim was to provide new information regarding the surface reactivity of bare and $\mathrm{Al}_{2} \mathrm{O}_{3}$-coated $\mathrm{LiCoO}_{2}$ and NMC by coupling adsorption of gaseous probe molecules $\left(\mathrm{NH}_{3}\right.$ and $\left.\mathrm{SO}_{2}\right)$ and XPS analyses. The results obtained after $\mathrm{NH}_{3}$ adsorption provide evidence that the surface reactivity toward this base probe molecule is very low for all materials. Moreover, we showed that hydroxyl groups are not present in significant amounts at the surface of these materials. The study of $\mathrm{SO}_{2}$ adsorption clearly evidences that $\mathrm{Al}_{2} \mathrm{O}_{3}$ coatings are effective to decrease the surface reactivity of $\mathrm{LiCoO}_{2}$ and $\mathrm{NMC}$ materials. In addition the results highlighted differences in the nature of adsorbed species for $\mathrm{LiCoO}_{2}$ and NMC and enabled 
us to propose an evolution from redox active sites and both acid-base and redox active sites, respectively. This work opens the door to further experimental approaches on other mixed transition metal oxides and theoretical studies to address the relevant adsorption mechanisms for in-depth understanding of the surface reactivity of such electrode materials.

\section{ASSOCIATED CONTENT}

\section{S Supporting Information}

XRD patterns and SEM micrographs of the bare and coated $\mathrm{LiCoO}_{2}$ and NMC materials. Tabulated specific area data. This material is available free of charge via the Internet at http:// pubs.acs.org.

\section{AUTHOR INFORMATION}

\section{Corresponding Author}

Phone: (+33) 5401750 06. Fax: (+33) 5594076 22. Email: delphine.flahaut@univ-pau.fr.

\section{Notes}

The authors declare no competing financial interest.

\section{ACKNOWLEDGMENTS}

The authors thank the Umicore company and its employees for the synthesis of $\mathrm{LiMO}_{2}$ samples and the fruitful discussions.

\section{REFERENCES}

(1) Yabuuchi, N.; Ohzuku, T. Novel Lithium Insertion Material of Li$\mathrm{Co}_{1 / 3} \mathrm{Ni}_{1 / 3} \mathrm{Mn}_{1 / 3} \mathrm{O}_{2}$ for Advanced Lithium-ion Batteries. J. Power Sources 2003, 119, 171-174.

(2) Park, S. H.; Shin, H. S.; Myung, S. T.; Yoon, C. S.; Amine, K.; Sun, Y. K. Synthesis of Nanostructured $\mathrm{Li}\left[\mathrm{Ni}_{1 / 3} \mathrm{Co}_{1 / 3} \mathrm{Mn}_{1 / 3}\right] \mathrm{O}_{2}$ via a Modified Carbonate Process. Chem. Mater. 2005, 17, 6-8.

(3) Kobayashi, H.; Arachi, Y.; Emura, S.; Kageyama, H.; Tatsumi, K.; Kamiyama, $\mathrm{T}$. Investigation on Lithium De-intercalation Mechanism for $\mathrm{Li}_{1-y} \mathrm{Ni}_{1 / 3} \mathrm{Mn}_{1 / 3} \mathrm{Co}_{1 / 3} \mathrm{O}_{2}$. J. Power Sources 2005, 146, 640-644.

(4) Ma, M.; Chernova, N. A.; Toby, B. H.; Zavalij, P. Y.; Whittingham, M. S. Structural and Electrochemical Behavior of $\mathrm{LiMn}_{0.4} \mathrm{Ni}_{0.4} \mathrm{Co}_{0.2} \mathrm{O}_{2}$. J. Power Sources 2007, 165, 517-534.

(5) Bentaleb, Y.; Saadoune, I.; Maher, K.; Saadi, L.; Fujimoto, K.; Ito, S. On the $\mathrm{LiNi}_{0.2} \mathrm{Mn}_{0.2} \mathrm{Co}_{0.6} \mathrm{O}_{2}$ Positive Electrode Material. J. Power Sources 2010, 195, 1510-1515.

(6) Bie, X.; Du, F.; Wang, Y.; Zhu, K.; Ehrenberg, H.; Nikolowski, K.; Wang, C.; Chen, G.; Wei, Y. Relationships Between the Crystal/ interfacial Properties and Electrochemical Performance of Li$\mathrm{Ni}_{0.33} \mathrm{Co}_{0.33} \mathrm{Mn}_{0.33} \mathrm{O}_{2}$ in the Voltage Window of 2.5-4.6 V. Electrochim. Acta 2013, 97, 357-363.

(7) Oh, S.; Lee, J. K.; Byun, D.; Cho, W. I.; Cho, B. W. Effect of $\mathrm{Al}_{2} \mathrm{O}_{3}$ Coating on Electrochemical Performance of $\mathrm{LiCoO}_{2}$ as Cathode Materials for Secondary Lithium Batteries. J. Power Sources 2004, 132, 249-255.

(8) Myung, S. T.; Izumi, K.; Komaba, S.; Sun, Y. K.; Yashiro, H.; Kumagai, N. Role of Alumina Coating on $\mathrm{Li}-\mathrm{Ni}-\mathrm{Co}-\mathrm{Mn}-\mathrm{O}$ Particles as Positive Electrode Material for Lithium-Ion Batteries. Chem. Mater. 2005, 17, 3695-3704.

(9) Oh, Y.; Ahn, D.; Nam, S.; Park, B. The Effect of $\mathrm{Al}_{2} \mathrm{O}_{3}$-coating Coverage on the Electrochemical Properties in $\mathrm{LiCoO}_{2}$ Thin Films. J. Solid State Electrochem. 2010, 14, 1235-1240.

(10) Huang, Y.; Chen, J.; Cheng, F.; Wan, W.; Liu, W.; Zhou, H.; Zhang, X. A Modified $\mathrm{Al}_{2} \mathrm{O}_{3}$ Coating Process to Enhance the Electrochemical Performance of $\mathrm{Li}\left(\mathrm{Ni}_{1 / 3} \mathrm{Co}_{1 / 3} \mathrm{Mn}_{1 / 3}\right) \mathrm{O}_{2}$ and its Comparison with Traditional $\mathrm{Al}_{2} \mathrm{O}_{3}$ Coating Process. J. Power Sources 2010, 195, 8267-8274.

(11) Machida, N.; Kashiwagi, J.; Naito, M.; Shigematsu, T. Electrochemical Properties of All-solid-state Batteries with $\mathrm{ZrO}_{2}$ coated $\mathrm{LiNi}_{1 / 3} \mathrm{Mn}_{1 / 3} \mathrm{Co}_{1 / 3} \mathrm{O}_{2}$ as Cathode Materials. Solid State Ionics 2012, 225, 354-358.
(12) Aurbach, D.; Markovsky, B.; Salitra, G.; Markevich, E.; Talyossef, Y.; Koltypin, M.; Nazar, L.; Ellis, B.; Kovacheva, D. Review on Electrode-electrolyte Solution Interactions, Related to Cathode Materials for Li-ion Batteries. J. Power Sources 2007, 165, 491-499.

(13) Dahéron, L.; Dedryvère, R.; Martinez, H.; Ménétrier, M.; Delmas, C.; Gonbeau, D. Electron Transfer Mechanisms upon Lithium Deintercalation from $\mathrm{LiCoO}_{2}$ to $\mathrm{CoO}_{2}$ Investigated by XPS. Chem. Mater. 2008, 20, 583-590.

(14) Andreu, N.; Baraille, I.; Martinez, H.; Dedryvère, R.; Loudet, M.; Gonbeau, D. New Investigations on the Surface Reactivity of Layered Lithium Oxides. J. Phys. Chem. C 2012, 116, 20332.

(15) Scofield, J. H. Hartree-Slater Subshell Photoionization Crosssections at 1254 and $1487 \mathrm{eV}$. J. Electron Spectrosc. Relat. Phenom. 1976, 8, 129-137.

(16) Moses, A. W.; Garcia Flores, H. G.; Kim, J. G.; Langell, M. A. Surface Properties of $\mathrm{LiCoO}_{2}, \mathrm{LiNiO}_{2}$, and $\mathrm{LiNi}_{1-x} \mathrm{Co}_{x} \mathrm{O}_{2}$. Appl. Surf. Sci. 2007, 253, 4782-1791.

(17) Dupin, J. C.; Gonbeau, D.; Vinatier, P.; Levasseur, A. Systematic XPS Studies of Metal Oxides, Hydroxides, and Peroxides. Phys. Chem. Chem. Phys. 2000, 2, 1319-1324.

(18) Biesinger, M. C.; Payne, B. P.; Grosvenor, A. P.; Lau, L. W.M.; Gerson, A. R.; Smart, R. St.C. Resolving Surface Chemical States in XPS Analysis of First Row Transition Metals, Oxides and Hydroxides: Cr, Mn, Fe, Co, and Ni. Appl. Surf. Sci. 2011, 257, 2717-2730.

(19) Allen, G. C.; Harris, S. J.; Jutson, J. A.; Dyke, J. M. A Study of a Number of Mixed Transition Metal Oxide Spinels using X-ray Photoelectron Spectroscopy. Appl. Surf. Sci. 1989, 37, 111-134.

(20) Brabers, V. A. M.; van Setten, F. M.; Knapen, P. S. A. X-ray Photoelectron Spectroscopy Study of the Cation Valencies in Nickel Manganite. J. Solid State Chem. 1983, 49, 93-98.

(21) Tsai, Y. W.; Hwang, B. J.; Ceder, G.; Sheu, H. S.; Liu, D. G.; Lee, J. F. In-Situ X-ray Absorption Spectroscopic Study on Variation of Electronic Transitions and Local Structure of $\mathrm{LiNi}_{1 / 3} \mathrm{Co}_{1 / 3} \mathrm{Mn}_{1 / 3} \mathrm{O}_{2}$ Cathode Material during Electrochemical Cycling. Chem. Mater. 2005, 17, 3191-3199.

(22) Kosova, N. V.; Devyatkina, E. T.; Kaichev, V. V. Optimization of $\mathrm{Ni}^{2+} / \mathrm{Ni}^{3+}$ Ratio in Layered $\mathrm{Li}(\mathrm{Ni}, \mathrm{Mn}, \mathrm{Co}) \mathrm{O}_{2}$ Cathodes for Better Electrochemistry. J. Power Sources 2007, 174, 965-969.

(23) Dahéron, L.; Martinez, H.; Dedryvère, R.; Baraille, I.; Ménétrier, M.; Denage, C.; Delmas, C.; Gonbeau, D. Surface Properties of $\mathrm{LiCoO}_{2}$ Investigated by XPS Analyses and Theoretical Calculations. J. Phys. Chem. C 2009, 113, 5843-5852.

(24) Dedryvère, R.; Foix, D.; Franger, S.; Patoux, S.; Daniel, I.; Gonbeau, D. Electrode/Electrolyte Interface Reactivity in HighVoltage Spinel $\mathrm{LiMn}_{1.6} \mathrm{Ni}_{0.4} \mathrm{O}_{4} / \mathrm{Li}_{4} \mathrm{Ti}_{5} \mathrm{O}_{12}$ Lithium-Ion Battery. $J$. Phys. Chem. C 2010, 114, 10999-11008.

(25) Kim, Y. J.; Cho, J.; Kim, T.-J.; Park, B. Suppression of Cobalt Dissolution from the $\mathrm{LiCoO}_{2}$ Cathodes with Various Metal-Oxide Coatings. J. Electrochem. Soc. 2003, 150, A1723-A1725.

(26) Guimon, C.; Zouiten, A.; Boréave, A.; Pfister-Guillouzo, G.; Schulz, P.; Fitoussi, F.; Quet, C. Surface and Subsurface Acidity of Faujasite-type Zeolites in Relation to their Composition: an XPS and TPD of Ammonia Study. J. Chem. Soc., Faraday Trans. 1994, 90, 3461-3467.

(27) Coluccia, S.; Lavagnino, S.; Marchese, L. Adsorption and Dissociation of Ammonia on the Hydroxylated Surface of Magnesium Oxide Powders. J. Chem. Soc., Faraday Trans. 1 1987, 83, 477-486.

(28) Datta, A.; Cavell, R. G.; Tower, R. W.; George, Z. M. Claus Catalysis. 1. Adsorption of Sulfur Dioxide on the Alumina Catalyst Studied by FTIR and EPR Spectroscopy. J. Phys. Chem. 1985, 89, 443-449.

(29) Lindberg, B. J.; Hamrin, K.; Johansson, G.; Gelius, U.; Fahlman, A.; Nordling, C.; Siegbahn, K. Molecular Spectroscopy by Means of ESCA II. Sulfur Compounds. Correlation of Electron Binding Energy with Structure. Phys. Scr. 1970, 1, 277.

(30) Ng, K. T.; Hercules, D. M. Studies of Nickel-tungsten-alumina Catalysts by X-ray Photoelectron Spectroscopy. J. Phys. Chem. 1976, 80, 2094-2102. 
(31) Guimon, C.; Gervasini, A.; Auroux, A. XPS Study of the Adsorption of $\mathrm{SO}_{2}$ and $\mathrm{NH}_{3}$ over Supported Tin Dioxide Catalysts Used in de-NOx Catalytic Reaction. J. Phys. Chem. B 2001, 105, 10316-10325.

(32) van Elp, J.; Wieland, J. L.; Eskes, H.; Kuiper, P.; Sawatzky, G. A.; de Groot, F. M. F.; Turner, T. S. Electronic Structure of CoO, Lidoped $\mathrm{CoO}$, and $\mathrm{LiCoO}_{2}$. Phys. Rev. B 1991, 44, 6090-6103. 